\title{
O SAGRADO ESTÁ NO TODO: EXPERIÊNCIAS DE PRATICANTES DO (NEO)PAGANISMO COMO POSSIBILIDADE DE ENCONTRO HOLÍSTICO DO SER
}

\author{
The sacred is in the whole: Experiences from practitioners of (Neo)Paganism as possibilities of the \\ being's holistic encounter
}

\author{
Lo sagrado está en el todo: experiencias de practicantes de (Neo)Paganismo como posibilidad de \\ un encuentro holístico del Ser
}

Susan SANae Tsugami

LUCIANA SANTOS

\begin{abstract}
Resumo: O artigo objetiva compreender as experiências dos(as) praticantes do Paganismo Contemporâneo e as relações que estes(as) possuem com suas práticas espirituais, assim como investigar como os mesmos compreendem e interagem com a natureza e como se percebem enquanto praticantes de uma crença holística. A partir de entrevistas em profundidade, com quatro praticantes do (Neo)Paganismo, pode-se analisar os discursos sobre as experiências espirituais, a partir da construção de duas categorias de análise: 1. Paganismo Contemporâneo: visão de mundo e práticas holísticas e 2. Compreendendo a Totalidade: a Natureza, o Self e a Comunidade. Pode-se apreender que a relação entre o sagrado, a natureza e a pessoa, no (Neo)Paganismo está definida pela noção de totalidade enquanto realidade na qual o mundo, os(as) deuses(as) e os seres vivos estão interligados e, por isso, entende-se que pessoa-mundo-sagrado não se separam. Palavras chave: Pagão. Religião. Espiritualidade.
\end{abstract}

\begin{abstract}
This paper aims to understand the experiences of practitioners of Contemporary Paganism and the relationships they have with their spiritual practices, as well as to investigate how they understand and interact with nature and how they perceive themselves as practitioners of a holistic belief. From in-depth interviews with four practitioners of (Neo) Paganism, it is possible to analyze the discourses on spiritual experiences through two categories of analysis: 1. Contemporary Paganism: Worldview and Holistic Practices, and 2. Understanding Totality: Nature, Self and Community. The research made it possible to understand that the relationship between the sacred, nature and the person in (Neo) Paganism is defined by the notion of totality as a reality in which the living beings, the world and the gods are interconnected, and therefore it is understood that the person-world-sacred does not separate.
\end{abstract}

Keywords: Pagan. Religion. Spirituality.

Resumen: El artículo tiene como objetivo comprender las experiencias de los practicantes del paganismo contemporáneo y las relaciones que tiene con sus prácticas espirituales, además de investigar cómo entienden e interactúan con la naturaleza y cómo se perciben a sí mismos como practicantes de una creencia holística. Basado en entrevistas en profundidad con cuatro practicantes del (Neo)Paganismo, es posible analizar los discursos sobre experiencias espirituales, basados en la construcción de dos categorías de análisis: 1. Paganismo Contemporáneo: cosmovisión y prácticas holísticas; 2. Comprensión de la totalidad: la naturaliza, el yo, y la comunidad. Es posible aprender que una relación entre o sagrado, naturaleza y persona, en (Neo)Paganismo, se define por la noción de totalidad con respecto a la realidade, en la que el mundo y los seres vivos están interconectados. Por lo tanto, se entiende que la persona-mundosagrado no se separa.

Palabras clave: Pagano. Religion. Espiritualidad.

\section{Ser-Humano, Ser-Espiritual}

Tentar definir o termo religião ou encontrar um simbolismo em comum entre as crenças religiosas é uma tarefa complexa. Os debates acadêmicos a respeito das possíveis definições do termo religião, por vezes, se depararam com ideias reducionistas, já que definições que visam a buscar uma compreensão universalista do que é a "religião" não são capazes de abranger todas as formas religiosas existentes no mundo. Koenig (2015) propõe uma definição abrangente para religião, como sendo um sistema de práticas e crenças relacionadas ao transcendente, baseadas em rituais e valores, observadas por uma determinada comunidade. Logo, percebese que, uma vez que cada sociedade, cultura, comunidade e campo religioso irá manifestar seus próprios processos simbólicos, entendimentos e interpretações a respeito de suas crenças, o termo "religião" se trata de um conceito amplo que deve ser entendido em suas inúmeras possibilidades de definições.

Levando em consideração os debates existentes a respeito do conceito, o presente estudo compreende as religiões enquanto um produto cultural, seguindo a definição proposta por Geertz (2008). O autor argumenta que as religiões devem ser entendidas 
enquanto um produto cultural, com padrões e significados que são transmitidos através da história de uma sociedade, gerando, assim, uma forma especifica de compreender o mundo circundante. Ele defende, ainda, que as religiões são sistemas simbólicos, cujas ideias, valores, comportamentos e senso estéticos produzem formulações de conceitos de ordem existencial.

Partindo do pressuposto de que a religião faz parte da história e da cultura da sociedade e entendendo o ser humano como um Ser relacional que é bio-psico-socio-espiritual, o estudo das religiões compreende o fenômeno religioso enquanto manifestação constituinte do ser humano. Por isso, faz-se necessário direcionar a percepção para a espiritualidade e para o pensamento religioso deste Ser, assim com avalia Freitas (2014). Ser este que é mobilizado pela experiência com o sagrado, com o transcendente, com experiências abstratas e misteriosas, que se permitem se influenciar em seus afetos, modificar propósitos de vida, valores, formas de se relacionar no mundo e, muitas vezes, ter até mesmo a sua saúde mental afetada por essas experiências (Koenig, 2012; 2015).

No âmbito de estudo da Psicologia da Religião, a compreensão do sentido religioso se dá pelo fato de que o ser humano, mesmo sendo biológico, está constantemente em construção através de sua história de vida, sendo influenciado pelo meio e pela cultura de onde vive. Para Amatuzzi (2010), é por meio das experiências do sujeito que se torna possível sua aproximação para a compreensão das próprias ações e pensamentos, e também com ideias construídas de forma artificial (como os estigmas, preconceitos, papéis sociais e muitos outros fatores que constroem formações de sentidos e de simbolizações). Através da aproximação com o vivido, podemos entender as diferentes maneiras do homem existir no mundo, já que cada pessoa possui uma maneira única de existir, de se relacionar e de se comportar.

A religiosidade e/ou a espiritualidade ${ }^{1}$ podem ser compreendidas como fatores importantes, por meio dos quais a pessoa se constitui humana. Para Ribeiro (2009), é pelo viés do contato com a espiritualidade que a pessoa percebe que não está sozinha no mundo e se torna passível direcionar o olhar para si mesma com compaixão, com amor, para, então, experienciar o encontro com o Outro. A espiritualidade permite que o ser humano olhe para dentro de si e se perceba em sua totalidade. O autor ressalta que esta noção de totalidade é fundamental para que o sujeito encontre sentido nas coisas e entenda que não cresce sozinho, uma vez que os

1 Espiritualidade e Religião, para os autores Hood, Hill e Spilka (2009), são termos que devem ser compreendidos de formas distintas. Espiritualidade se refere à uma conotação pessoal e psicológica, envolve crenças, valores e comportamentos de uma pessoa. Já o termo religião está relacionado a questões mais institucionais e sociológicas do que pessoais, nesse sentido, a religiosidade de uma pessoa denota o envolvimento com uma tradição e instituição religiosa. seres humanos são, em essência, seres relacionais. No âmbito da compreensão da Psicologia, entende-se que é através da interação do sujeito com seu meio, com outras pessoas e com realidades que se torna possível identificar-se, perceber-se e diferenciar-se enquanto sujeito único, em sua forma de ser e de estar no mundo.

Ainda sobre o sentido de contato com o Outro, Ribeiro (2009) problematiza a concepção do Eu em nossa sociedade, apontando que este Eu passou a ser compreendido enquanto processo que se constitui de maneira independente da realidade que cerca a pessoa, consequentemente perdendo de vista a noção da totalidade e sua contextualização. Essa visão foi construída, no viés científico, ao se compreender o ser humano como um ser subdividido em duas partes separadas, quais sejam mente e corpo, que foram, por muito tempo, compreendidas como realidades sem relação direta uma com a outra. Para o autor, o Ser passou a ser percebido de maneira a não prestar atenção na realidade externa e, com isso, começou a serem assegurados, nas relações sociais, olhares egoístas, egocêntricos e individualistas. Esta posição psicológica separou a Pessoa do Outro, da natureza e do mundo; com este afastamento, os seres humanos passaram a não viver o sentimento de pertencimento ao planeta e ao universo, uma vez que Pessoa e Mundo deixaram de ser vistos como Totalidade. $\mathrm{O}$ autor ainda elenca que estes entendimentos geraram consequências, visto o fato de que seres humanos deixaram de vivenciar o sentimento de Totalidade e passaram, assim, a cortar árvores sem remorso, jogar lixo e sujar as ruas sem consciência, deixando de perceber que estão em relação íntima com todas as coisas existentes no mundo e no universo.

O encontro do sentido religioso é complexo. Talvez por conta disso, observa-se que é incontestável o fato de que grande parte da população demonstra, de alguma forma, a necessidade de buscar alguma espiritualidade, crença ou religião. Segundo Hood et al. (2009), existem dois fatores importantes a serem discutidos sobre esta compreensão: o encontro do sentido da vida e a tentativa de obtenção de controle, ambos por meio da religião. $\mathrm{O}$ primeiro fator diz respeito ao encontro de sentido e significado, que não necessariamente está relacionado ao pensamento religioso em si, mas ao encontro daquilo que faz sentido para a pessoa em sua experiência existencial. Justamente devido a esse detalhe é que tal busca pode se manifestar até mesmo por meio de uma relação com o discurso científico; com o próprio ateísmo; com a prática de atividades espiritualizadas (yoga, por exemplo); com o contato com a natureza; com o encontro e com a busca por uma religião, dentre diversas outras formas que possam ensejar sentido às coisas e que certamente variam de uma pessoa para outra. Sobre a questão do encontro religioso, o autor identifica as crenças e a religiosidade como aspectos mais abrangentes de todos os sistemas de 
significado, pois eles podem abarcar muitos fatores, como o trabalho, a família, a realização, as relações pessoais, os valores e os ideais.

É possível observar, também, que a religião possibilita o contato com uma série de aspectos relacionados tanto ao âmbito pessoal (sentimentos, emoções, ações), quanto ao social (relações pessoais, valores, crenças, ambiente). Neste sentido, ela fornece uma gama de propriedades que envolverão o sujeito em sua totalidade. Hood et al (2009) expõem que, além de todos esses fatores mencionados, a religião pode proporcionar direcionamento e foco para aquilo que está "além de mim", ou seja, além da pessoa em sua existência, tanto no sentido de algo elevado e transcendente, quanto no sentido de proporcionar uma forma de se situar perante a necessidade de domínio, controle e poder sobre o mundo.

Um importante conceito para elucidarmos o modo como o ser humano estabelece seu contato com o outro e com a religião é o holismo. Diante da área das ciências da saúde, da qual a Psicologia faz parte, este conceito surgiu e passou a ser difundido enquanto categoria que possibilita um novo olhar para compreender o ser humano, abrangendo a noção de totalidade diante da complexidade da existência humana. Paiva (1998) discorre sobre a ideia de holismo, que começou a emergir em muitos discursos religiosos e espirituais, a partir da segunda metade do século XX. Os movimentos espirituais alternativos de então se difundiam em seus discursos e propostas de possibilidades de encontro holístico do Ser. Crenças fundamentadas na natureza e em seus ciclos passaram a permitir a observância da difusão desses sentidos sobre a conscientização e o sentimento de pertencimento à natureza e ao planeta. Com isso, diante da proposta de estabelecer uma reconexão do ser humano com o mundo natural, o holismo torna-o uno com a natureza e seus ciclos, estabelecendo um contraponto ao pensamento do materialismo mecanicista que imperava como sentido da existência.

Um exemplo de religião que se popularizou em meio a esse discurso de conexão com o mundo natural é justamente o Paganismo Contemporâneo, que começou a se estabelecer com a proposta de resgate de uma religião "original" que fosse anterior ao Cristianismo. Com isso, ideias romantizadas sobre a natureza e as crenças ancestrais se mesclam com todo o discurso dos movimentos espirituais que haviam começado a surgir na Europa Ocidental, especificamente no contexto do pós-guerra. O movimento da Nova Era se constituiu como forma de expressão da espiritualidade ocidental que ganhou espaço com o declínio da popularidade das instituições religiosas. Segundo York (2004), a Nova Era se consolidou paralelamente ao aumento do secularismo enquanto opção não-religiosa capaz de ajudar no desenvolvimento do self e no despertar da consciência. Com isso, religiões alternativas ganharam diferentes configurações, como a Nova Era, o (Neo)Paganismo e a Ideologia Secular.

Conforme o mesmo autor, algo que contribuiu fortemente para o surgimento dessas novas formas de espiritualidade e religiosidades foi a "era da informação" e do aculturamento. Esses processos carregavam consigo o questionamento e o despertar do interesse, por parte das pessoas, em inúmeras crenças e práticas religiosas existentes no mundo. Em conjunto ao discurso do transcendentalismo, das tradições metafísicas, do espiritualismo e da teosofia, os movimentos espirituais de 1960 deixaram à parte qualquer discurso prévio sobre uma espiritualidade imposta, configurando-se, assim, como movimento integrante da contracultura. $\mathrm{O}$ autor ressalta que um dos legados da contracultura da década de 1960 foram tanto a New Age, quanto o Paganismo Ocidental Contemporâneo; este aglomerava o animismo $^{2}$, o politeísmo e o paganismo antigo.

Os movimentos espirituais alternativos surgiram, portanto, a partir de um modo distinto e não ortodoxo (ao menos não nos moldes institucionais) de lidarem com suas espiritualidades, seus corpos e suas subjetividades. A partir desse momento, as transformações passaram a ser vivenciadas sob novos referenciais que interagiam com a subjetividade e, por fim, estabeleceram novas maneiras de se buscar as religiões, necessidades essas que emergiram com as demandas do mundo moderno. Sendo assim, para compreender os discursos religiosos e as diversas manifestações de Paganismos Contemporâneos, é preciso levar em consideração a compreensão da totalidade na qual o universo (Neo)Pagão está inserido. Tratam-se, assim, de crenças que, segundo Gunnell (2015) e Strmiska (2005), transitam entre um paganismo antigo précristão (histórico) e um paganismo ressignificado e adaptado ao mundo contemporâneo, uma vez que as concepções, as transformações e as ressignificações são produções de sentidos formadas a partir das necessidades sociais demandadas pela modernidade e pelo mundo contemporâneo.

Os Novos Movimentos Religiosos começaram a ser difundidos por volta da década de 1960 e, paralelamente, o Paganismo Contemporâneo despontou. Este se estabeleceu ao despertar interesse daqueles que não estavam satisfeitos com os discursos religiosos do Cristianismo e, assim, cativou, também, inúmeros interessados pelo ocultismo. Ainda que o (Neo)Paganismo seja considerado um movimento à parte dos Novos Movimentos Religiosos, o cenário do Paganismo Contemporâneo está influenciado por todo esse contexto histórico no qual emergiu. Compreendemos, assim, o Paganismo Contemporâneo como releitura e ressignificação que busca, em sua diversidade, resgatar aspectos de

\footnotetext{
2 Animismo: deriva da palavra latina "anima” que popularmente pode ser interpretado por "alma”. Existem um extenso debate sobre seu significado pois pode ser interpretado de diferentes formas dependendo da cultura e da religião (HARVEY, 2014).
} 
diversas crenças religiosas de períodos pré-cristãos, ou seja, constitui em crenças pagãs resgatadas e adaptadas ao mundo contemporâneo, relacionandose às crenças politeístas de sociedades nórdicas, gregas, egípcias, celtas, romanas, dentre outras que são utilizadas como inspiração para o resgate das práticas e das crenças religiosas antigas.

Segundo o entendimento de York (2003), o próprio termo paganismo é complexo de ser definido, podendo ser compreendido como amplo e polimórfico. Deste modo, o sagrado pode assumir diferentes formas. Entende-se, portanto, o paganismo como um conceito extenso que necessita ser definido por características que, apesar de fixas e estabelecidas, não sufoquem a variedade desses sistemas possíveis de crenças que se manifestam em pluralidades. O termo "paganismo" originalmente se referia às pessoas que residiam no campo; em contrapartida, ele, posteriormente, acabou por receber uma conotação pejorativa, no sentido de que houve uma apropriação dessa utilização para se definir o "não-cristão", no sentido de herege. Já o (Neo)Paganismo ou Paganismo Contemporâneo, refere-se às releituras e ressignificações das crenças de sociedades pré-cristã, sendo, portanto, considerado um movimento da contemporaneidade. White (2016) ressalta que é de suma importância compreender as problemáticas de definições dos termos utilizados para descrever e se referir a essa crença religiosa, uma vez que há inúmeras discordâncias entre acadêmicos e praticantes, já que as terminologias adotadas pelo meio acadêmico, frequentemente, são contestadas dentro da própria comunidade "Pagã". Fato esse que ilustra a dificuldade do diálogo entre os adeptos e os estudiosos do tema, demonstrando, assim, a necessidade emergente do meio acadêmico buscar compreender e discutir temáticas voltadas ao fenômeno do Paganismo Contemporâneo.

White (2016) argumenta que o Paganismo Contemporâneo pode ser interpretado das seguintes formas: como uma religião nova do século XXI, baseada no culto da natureza e nas tradições indígenas; como uma religião politeísta, baseada na natureza, recriando formas de se relacionar com a Terra e com os seres vivos e resgatando uma sabedoria antiga; como uma religião singular. Entenderemos também que encontram-se inseridas, nesta categoria (Neo)Pagã, as religiões e crenças que possuem relação holística com o sagrado e que sejam compreendidas de forma imanente, ou seja, em que o divino, a natureza e os seres vivos não se separam, estão interligados e são concebidos de forma codependente. Sendo assim, são consideradas religiões (Neo)Pagãs: a Bruxaria Moderna, o Paganismo Contemporâneo, a Religião da Deusa, o Druidismo Contemporâneo, o Ásatrú ${ }^{3}$, a Religião

3 Para maiores informações sobre o Paganismo Nórdico no Brasil, ver: Langer, J. Asatrú: Um Guia Essencial Para o Paganismo Nórdico. Revista Brasileira de História das Religiões, v. 3, n. 7, 2010, p. 359362. Resenha.
Wicca $^{4}$, dentre outras diversidades e variações de (Neo)Paganismos existentes no mundo (TSUGAMI, 2019).

Outro aspecto importante a ser ressaltado é o fato de que as pessoas que encontram sentido religioso nas crenças Pagãs Contemporâneas comumente relatam sentir uma profunda ligação e identificação com crenças religiosas de sociedades europeias do passado pré-cristão. Neste sentido, há um sentimento de conexão com um passado histórico romantizado das culturas europeias, que, muitas vezes, são entendidas, pelos praticantes, como povos em condição agrária e que viviam em uma profunda conexão com a terra, dependentes da agricultura, da caça, da comunidade e das batalhas. A proposta do presente trabalho surge ao se fazer notar a relevância em compreender a dimensão religiosa/espiritual no processo de subjetivação do ser humano, que é bio-psico-social-espiritual, e de apreender esses movimentos religiosos atuais com leituras de fé ainda pouco visibilizadas no ambiente acadêmico. Busca-se, dessa forma, compreender as experiências dos(as) praticantes do Paganismo Contemporâneo e as relações com suas práticas espirituais; investigar de que maneira os próprios enxergam e interpretam sua relação com a natureza; e, por fim, descrever como eles se percebem enquanto praticantes de uma crença holística.

\section{Metodologia}

Pelo caráter exploratório do trabalho realizado com um grupo específico, lançou-se mão do método qualitativo de pesquisa, através de amostra não probabilística, pelo método de "bola de neve" (Goodman, 2011), para acessar os participantes de maneira conveniente. Nesta pesquisa, foram entrevistados quatro sujeitos, sendo dois homens e duas mulheres que escolheram vertentes do Paganismo Contemporâneo como crenças religiosas, sendo um homem e uma mulher pertencentes a um grupo religioso, e os outros não pertencentes a grupos, com práticas religiosas individual/solitária.

Após contatados(as) e confirmado o interesse com os(as), foram agendadas as entrevistas individuais com cada um(a) deles(as), em lugares de suas preferências. Cada encontro teve três momentos: primeiramente, foram esclarecidos os objetivos da pesquisa, lido e assinado o Termo de Consentimento Livre e Esclarecido ${ }^{5}$; posteriormente, foi realizada a entrevista em profundidade, a partir de um questionário semiestruturado, com perguntas abertas, desenvolvidas a partir de eixos estruturantes sobre a temática em estudo; e, por fim, foi entregue um questionário sociodemográfico, para caracterizar os(as) participantes, que responderam

4 Ver: Terzetti, C. L. (2016). A deusa não conhece fronteiras e fala todas as línguas: um estudo sobre a religião Wicca nos Estados Unidos e no Brasil (Tese de Doutorado em Ciência da Religião). Universidade Pontifícia Católica de São Paulo.

5 Essa pesquisa foi analisada e aprovada pelo Comitê de Ética em Pesquisa sob o número de CAAE 16639413.1.0000.0029. 
de próprio punho. As entrevistas foram gravadas e, posteriormente, transcritas para melhor realização da análise, que foi feita a partir do método de Análise de Discurso (BRANDÃO, 2004).

\section{Resultados}

A partir da análise das narrativas trazidas pelos discursos dos(as) participantes, compreendido o que há de comum nas experiências, foram construídas duas categorias para compreensão do material apreendido nas entrevistas: Paganismo Contemporâneo (visão de mundo e práticas holísticas); e Compreendendo a Totalidade (a Natureza, o Self e a Comunidade). Todavia, no intuito de se individualizar as experiências, inicialmente será apresentado um resumo das experiências dos(as) quatro participantes e de suas respectivas identificações religiosas.

\section{Participantes do Paganismo: Experiências com o holismo}

Carina $^{6}$ (23 anos) é praticante solitária (não pertence a nenhum um grupo) do Paganismo Contemporâneo. Ela compreende que o (Neo) Paganismo é como uma busca interior, um aspecto muito importante de sua vida; relata estar constantemente se atualizando com leituras, com a finalidade de buscar novos conhecimentos dentro do que acredita, uma vez que é o que lhe traz equilíbrio. Ela conta que sua avó possuía uma biblioteca com muitos livros sobre Budismo e, por volta dos 12 e 13 anos, ao explorar o acervo, teve contato com seus primeiros livros sobre magia. Desde então, continuou a estudar e praticar magia. Carina relata que ser praticante do (Neo)Paganismo a faz perceber que: "Eu não me sinto vetada a fazer certas coisas só porque todo mundo faz, eu vejo como tipo, como é bom botar a mão na terra e sentir a energia assim, sentir a energia das pessoas e saber o porquê daquilo (...)."

Pamela (24 anos) se identifica como Pagã pertencente a um coven (nomenclatura utilizada para definir um grupo religioso de algumas vertentes do Paganismo Contemporâneo). Ela nasceu em um contexto familiar cristão e relatou que, aos 13 anos, sentiu-se insatisfeita com a religião de seu meio familiar. "Eu era insatisfeita com a explicação que eu tinha na minha religião anterior e eu fui procurar respostas em outra religião e foi assim que eu encontrei, de início, a Wicca e, depois, eu me tornei Pagã (...)” Para a entrevistada, a religião anterior não proporcionava o acolhimento de seus anseios; relatou ter tido sonhos cujos significados ela não compreendia, até que, então, leu o primeiro livro sobre Wicca, quando começou a ter suas necessidades respondidas. Assim, seu interesse foi despertado e sua identificação com o (Neo)Paganismo começou.

$6 \quad$ Os nomes utilizados para identificar os praticantes são fictícios para preservar a privacidade e sigilo, a fim de evitar quaisquer constrangimentos aos participantes.
Sobre o assunto, relata: "Então, eu digo que você não bem escolhe, né? Você é meio que escolhido."

Arthur (24 anos) é Ásatrú (uma das vertentes do Paganismo Contemporâneo Nórdico), considerase Pagão Solitário, ou seja, não pertence ou frequenta um grupo religioso específico dentro do (Neo) Paganismo; relatou que também cresceu inserido no meio religioso de seus pais, porém sempre se percebeu questionando o pensamento da religião Evangélica de sua família: "Como eu não me senti satisfeito no mundo cristão que eu era inserido na época e, mesmo com 13 anos de idade, isso já era bem forte, já era bem nítido, sabe?". Para ele, foi ao começar a estudar os ensinamentos cristãos de uma forma mais crítica que percebeu não concordar e não se identificar com eles. A partir de então, passou a procurar, por conta própria, uma crença alternativa. Ele relata que seu primeiro contato com o Paganismo Contemporâneo foi por meio da internet: "O primeiro contato foi pela internet, como acho que é para a maioria dos praticantes, né? Eu sempre senti uma curiosidade muito grande por uma espiritualidade alternativa".

O questionamento e a falta de identificação com a religião também se fizeram presentes para Paulo (34 anos), atualmente praticante da Religião Wicca. Ele relata que, desde criança, frequentou centros Kardecistas, a Umbanda, Igreja Católica e que, devido à essa variedade de religióes frequentadas por sua família, ele sempre esteve, desde muito novo, interessado pela astrologia e pela magia. Ele relata: "Quando eu estava com 21 para 22 anos que eu comecei a ficar desgostoso com o Kardecismo(...) foi quando uma amiga, que é bruxa, resolveu me apresentar o grupo que faz rituais públicos lá no [nome do local] (...), foi no dia [cita a data], foi o Beltane ${ }^{7}$ de 2001".

\section{Paganismo Contemporâneo: visão de mundo e} práticas holísticas

Todos(as) os participantes relataram experiências anteriores em outras religiões. Segundo eles(as), o primeiro contato religioso esteve relacionado às crenças predominantes no ambiente familiar, nas quais não encontravam sentido ou, então, faltava uma identificação religiosa plena. A religião embasada em ensinamentos cristãos não alcançou, nos(as) entrevistados(as), sentido pessoal. E foi nesse momento que passaram a buscar suas espiritualidades em outras crenças, no caso, no Paganismo Contemporâneo. Curioso perceber que essa mudança ocorreu no período da adolescência, período marcado pela busca da própria identidade e pela necessidade de se impor no mundo de forma autêntica.

Esses relatos sobre a busca religiosa encontram consonância com a compreensão de Amatuzzi (2010), ao explicar que a busca pela religião começa

$7 \quad$ Beltane é um dos rituais celebrados do calendário (Neo)Pagão conhecido como A Roda do Ano. 
com a inquietação de um sentido religioso e que, em seguida, há a experiência religiosa propriamente dita. A busca religiosa está relacionada aos valores pessoais do sujeito, ou seja, àquilo que lhe provoca identificação. Em diversos casos, é muito comum que a religião dos familiares seja seguida e entendese, assim, que ela constitua um primeiro contato e uma referência de valores que existem dentro do contexto de cada sujeito, como percebeu-se nos(as) participantes mencionados. $\mathrm{O}$ autor explica que a inquietação religiosa se refere a um vazio que habita a pessoa, já a experiência religiosa está relacionada ao preenchimento deste vazio através do encontro com algo percebido como real, que está fora da pessoa. Estas experiências são complementares, de forma que uma sem a outra torna-se vazia e passa a perder propósito e sentido. Também ressalta que a inquietação religiosa diz respeito a um conhecimento de si mesmo, configurando um processo de autoconhecimento que envolve desejos e aspirações. A experiência religiosa, então, viria ao encontro efetivo com algo outro, que é capaz de preencher o vazio existencial. Da forma que os(as) participantes trouxeram as suas experiências no (Neo)Paganismo, pode-se perceber a busca de sentido e significado da espiritualidade e da religiosidade como possibilidades oriundas da procura do sujeito em se tornar um Ser integrado, a partir daquilo que dá sentido e que proporciona, à pessoa que experiencia e se identifica, uma forma para interagir com seu vazio existencial.

Para Ribeiro (2009), a espiritualidade é algo interno que está relacionado à subjetividade e à experiência de mundo. É um processo de “centramento" e equalização do qual a pessoa faz uso, no mundo, para evoluir, no sentido de crescimento e desenvolvimento por meio de suas experiências. É possível perceber na fala dos participantes, que a relação estabelecida por eles com suas crenças religiosas está ligada a uma forma de contato com o meio e com eles mesmos, indo ao encontro de algo para se tomar consciência da relação pessoa-mundo de forma interligada. Esse aspecto é compreendido ao passo que os sujeitos se percebem em uma visão de mundo relacionada à conexão com a natureza. Dentro dessa compreensão, a relação com o vivo, com o mundo e com a natureza está fortemente relacionada e conectada a todas as coisas que existem, logo, o homem (divino) e a natureza (divina) não são separáveis. Concluem, desta forma, que o sagrado está em si mesmo, bem como que o sagrado está no todo:

“(..) conforme a gente se aprofunda nesse conhecimento espiritual, a gente percebe a divindade de uma maneira mais abrangente do que uma religião só consegue expressar, e o paganismo te permite estudar tantos outros caminhos que você tiver interesse sem que isso te cause uma crise existencial. (...) outra coisa que eu gostei muito, desde que eu conheci o paganismo, foi isso, que a sacralidade não se resume a um lugar específico, tem uma Igreja que é um lugar especial. A gente aprende que a presença divina, ela é difusa, ela existe em todo lugar, então é possível fazer uma celebração no Parque da Cidade, que seja, ou uma cachoeira próxima a [nome da cidade] (...).” (Arthur).

Para vivenciarem a religião, os(as) entrevistados(as) relatam que não há um limite de espaço ou local, já que a sacralidade não se resume apenas a um aspecto da existência, mas está em relação constante com a natureza e a totalidade. Para eles(as) é possível, portanto, entrar em contato com o divino em qualquer lugar. Como é possível observar no relato acima, o Paganismo Contemporâneo não é uma religião que possui um templo ou uma instituição unificada. Ainda que muitos grupos possam estabelecer lugares fixos de encontro para os rituais e reuniões, o "espaço sagrado" se constitui por meio da compreensão de que há uma totalidade e conexão entre todas as coisas.

"Nosso sagrado tá aqui (...) tá tudo encadeado, tudo formando uma grande teia (...) Viver essa espiritualidade é viver. Quando eu digo viver essa espiritualidade, é muito mais viver do que essa espiritualidade, entende? É, é estar vivo. Essa conexão com o todo se dá o tempo todo” (Paulo).

Nesse e nos demais relatos dos(as) participantes sobre suas respectivas vivências e relações com o espaço de práticas, relações com a natureza e com o sagrado, é percebida a integralidade que perpassa o holismo, entendendo-se que pessoa-mundo-sagrado não se separam. A relação entre o sagrado, a natureza e a pessoa, no (Neo)Paganismo, está relacionada à noção de totalidade enquanto realidade na qual o mundo, os deuses(as) e os seres vivos estão interligados (Strmiska, 2005). Para Ribeiro (2006), a noção de totalidade se dá no momento em que as partes são percebidas de "inter" e "intrarrelação" em "inter" "intradependência”, formando uma unidade de sentido. Desta forma, a espiritualidade vivenciada pelos(as) entrevistados(as) permite, a eles(as), a percepção do ser humano enquanto parte da natureza, em sua essência, sem que haja uma separação entre pessoa-mundo-sagrado. Segundo o autor, esta experiência do Todo permite uma vivência de encantamento de ser-mundo-no-mundo, em que o homem, enquanto compreendido em sua espiritualidade, está “encarnado no mundo” e está no mundo em sua essência, permitindo, a partir disso, uma contemplação do mundo com o Outro. Percebendo-se como existente, contempla, então, a sua própria existência e descobre que o mundo e ele são aspectos constituintes da mesma realidade. 
"Eu vejo como algo natural, é algo que faz parte, eu acho que faz parte do ser humano. Se as pessoas parassem um pouco pra dedicar um tempo, sentir a energia da terra, que ela é muito pulsante; se você se concentrar, você sente. Tá na terra, tá no ar, tá na água, tá na comida que você come. Então, se o ser humano se conectasse mais com a deusa mãe, teria mais respeito também pela terra. Não teria tantos problemas com poluição, com devastações. Porque o ser humano deixou de se importar com o que ele vive.” (Pamela).

Observou-se, como aspecto comum entre os(as) participantes, a percepção de pertencimento da pessoa-no-mundo. Nesse sentido, compreende-se o Paganismo Contemporâneo enquanto possibilidade de vivência espiritual que permite o encontro holístico do Ser, já que o entendimento religioso e as práticas são percebidas, pelos adeptos, como uma forma de resgate da interação que integra a pessoa com o mundo. Encontro e integração estes que têm pautado até mesmo um "ethos nova era que o aproximam do universo mágico-religioso” (Guerriero et. al., 2020, p.118). Dessa maneira, é gerado um sentimento de pertencimento ao planeta e, através disso, possibilita-se a percepção de unidade, conforme podemos observar nas falas relatadas:

"Nossa, é, é muito assim, eu não sei explicar direito, eu sinto muito assim, tipo, quando eu tô perto da natureza, eu me sinto calma, me dá paz, assim, quando eu tô perto de certas pessoas, eu me sinto muito bem, quando eu tô perto de pessoas que não são muito legais, aquilo passa pra mim... Eu sou como se fosse um imã sabe? Eu consigo sentir muito a energia das coisas, muito mesmo. Eu tenho essa sensibilidade desde criança, então, tudo, tudo se eu não tenho o controle, tudo interfere na minha vida, entendeu?" (Carina).

“(...) Mas eu me sinto conectado com o divino, de fato, eu me sinto junto, eu me sinto inteiro(...). Eu entendo que, quando uma pessoa se inicia, ela faz um juramento de serviço aos Deuses. (...), o divino não está à parte de nós, mas ele é parte de nós. Então, quando eu faço um juramento de serviço aos Deuses, eu faço um juramento de serviço no Deus que está em cada pessoa e que não é diferente dos Deuses que permeiam toda a natureza, essa noção de conexão, de estar conectado a tudo e a todos é parte central da minha espiritualidade (...).” (Paulo).

“(...)Então, é uma prática que você vê muita aplicação na sua vida inteira em todas as áreas da vida, existem orientações que você recebe tanto de grupos quanto de materiais escritos, livros, sobre preservar a natureza, entrar em contato com a natureza e, assim, coisas simples, andar descalço de vez em quando, tomar banho de cachoeira, enfim, são ideias que são passadas pro pagão que eu noto, eu sinto falta em outras religiões que eu já estudei. O templo é você, e você é o mundo, então, foi um motivo forte pra eu ter escolhido esse caminho.” (Arthur).

Segundo os relatos dos praticantes, os ensinamentos e as orientações que são transmitidas, baseadas nas suas crenças e no sentimento de totalidade e de pertencimento ao planeta, propõem possibilidades de responsabilização pela natureza. Nesse sentido, há uma compreensão ecológica diante do mundo. Esses relatos vão ao encontro do que Ribeiro (2009) chama de Mente Holística. Esta mente fomenta a preparação para uma espiritualidade engajada, sendo a Espiritualidade Cósmica aquela que gera sentido ao agir humano. $\mathrm{O}$ autor explica que a mente está profundamente relacionada ao movimento do Universo, pois este também se encontra em um movimento de transcendência. A pessoa, ao se perceber como parte deste processo, permite, então, uma noção ecológica e uma ressignificação da relação com o Planeta. Para o autor, somos seres "biopsicossocioespirituais" (p. 84), sendo o ser humano uma expressão eloquente da natureza. Portanto, nos situamos no Universo de diversas maneiras enquanto seres humanos: corpo, mente, ambiente e espírito vivem em "intrarrelação" com o mundo, que, por si, não é algo que esteja fora das pessoas. Em última instância, somos seres de relação do mundo e no mundo, logo, há um senso de responsabilidade do agir, partindo de uma experiência ecológica.

O Paganismo Contemporâneo sugere uma harmonização com o "cosmos”, com o planeta e com o corpo. Segundo Clifton (2009), as relações entre os praticantes e o sagrado são compreendidas em totalidades, constituindo a experiência religiosa no entendimento de que o ser humano faz parte da natureza e, com isso, as práticas religiosas estão embasadas no andamento do sol, da lua e, por consequência, nos ciclos da natureza. Sendo assim, muitos adeptos consideram suas crenças como centradas na natureza e compreendem o mundo natural como estando intimamente conectado com eles mesmos. Por isso, a natureza se torna um aspecto inseparável dos deuses, dos seres e das pessoas, tornando-se parte de seus corpos e de sua experiência humana. Como se percebe, o entendimento da relação entre o (Neo)Paganismo e suas concepções da sacralidade da natureza é algo comumente encontrado nos discursos dos praticantes. Contudo, é importante ressaltar que, dentro da categoria (Neo)Pagã há uma diversidade extensa de vertentes culturais, panteões e grupos, e que, portanto, o (Neo) Paganismo é compreendido como uma categoria religiosa contemporânea dentro 
da qual todas essas manifestações se encontram. Por não se tratar de religiões com propostas "dogmáticas”, essas concepções certamente podem apresentar suas variações em relação à sua concepção com o planeta, como visto em Strmiska (2005), Tsugami (2019) e York (2003).

\section{Compreendendo a Totalidade: a Natureza, o Self e a Comunidade}

Independente das variações em relação ao planeta, para os (Neo)Pagãos, a conexão com a natureza se torna um aspecto importante para suas práticas religiosas. Lugares isolados, com predominância do mundo natural, propõem uma experiência que possibilita o sentir das "energias" dos espaços e lugares tidos como sagrados, assim como permitem sentir e conectar-se com as entidades e elementais. Em relação a esse aspecto, Harvey (2009) explica ser costumeiro, nos discursos dos Pagãos Contemporâneos, o entendimento deles ao relacionarem suas crenças como "animistas". Para o autor, o (Neo)Paganismo se funde entre barreiras fluidas em conceitos não sistematizados sobre a natureza, por se tratar de uma religião "sem dogmas", permitindo uma diversidade de "sistematizações" e interpretações entre os grupos ou praticantes solitários. O animismo contemporâneo, quando compreendido sob o olhar do (Neo)Paganismo, referese aos seres "não-humanos" como, por exemplo, os elementais, os espíritos da natureza, as entidades, as árvores e alguns objetos inanimados como estátuas, amuletos e pedras de um local antigo ou "sagrado". Em suma, prevalece o entendimento de que os seres humanos representam apenas um aspecto da existência e, assim como eles, outras formas de vida existem nas diversas dimensões da realidade.

Foi possível perceber claramente esses aspectos quando os(as) praticantes relataram sobre as concepções holísticas das suas práticas religiosas. Lugares próximos à natureza, como cachoeiras ou locais mais isolados, longe de habitação humana, proporcionam a eles a sensação de conexão e possibilidade de encontro com essas outras formas de existência. Práticas meditativas e rituais para as fases da lua, sazonalidade e outros formas ritualísticas são aspectos centrais para a compreensão religiosa dessas pessoas. A entrevistada Pâmela explica que, para se conectar com a Deusa, realiza meditações que possibilitam esse encontro. Outras meditações são feitas, por ela, com o propósito de manter essa conexão com outros seres que estão além dos humanos. Assim, são realizadas práticas religiosas, meditativas e exercícios com o propósito de harmonização com todos esses aspectos da religião:

"São meditações pra conectar com a Deusa, pra conectar com os elementais. Os elementais seriam o dos quatro elementos né?, fogo, ar, água e terra. Então esses exercícios pra você conectar sua energia com a energia da mãe. Porque a terra é a mãe ne. Então quando você coloca o pé no chão, pode sentir a energia da mãe. Então a gente faz esses exercícios, essas práticas. É meditação pra poder conectar essa energia, com a sua, do seu corpo, e, poder se equilibrar também.” (Pamela).

Em estudos clássicos sobre o $(\mathrm{Neo})$ Paganismo, Berger (1999) e Pike (2001) investigam e compreendem outra característica da referida religião, que diz respeito ao desenvolvimento do Self mágico. As práticas do (Neo)Paganismo propõem, enquanto possibilidade, a experiência da consciência dos vários aspectos que constituem a identificação dos praticantes enquanto sujeitos. Em um aspecto geral, é possível observar que os adeptos do Paganismo Contemporâneo se percebem enquanto sujeitos espiritualizados, levando consigo muitos símbolos religiosos que os permitem estar em contato constante com sua identidade religiosa. Um exemplo, assim como observado nos(as) participantes, são os amuletos. É comum entre os praticantes, independentemente de qual panteão ou vertente (Neo)Pagã seguida, a utilização de pingentes e adereços pessoais, tais como pentagramas ${ }^{8}$, triskelions $^{9}$ e mjölnir ${ }^{10}$, dentre outros diversos símbolos que os fazem ser identificados dentro da categoria "pagã" em suas respectivas vertentes. Devido às diferentes percepções sobre o sagrado e as práticas religiosas, Berger (1999) elucida que as peculiaridades de cada religião direcionam diferentes desenvolvimentos da constituição do Self da pessoa. Segundo a autora, em relação ao cenário do (Neo)Paganismo, as práticas ritualísticas possuem tanto aspectos psicológicos, quanto místicos. Paulo relata:

“Toda relação, ela é sagrada, ela é divina por natureza (...) tomar esse estado de consciência só foi possível no momento que eu comecei a praticar, comecei a entender o real significado da minha religião. Esse processo de conexão com o meu divino interior, por outro lado, ele começou a assumir outras formas, ne (...) cada pessoa é forjada por um princípio, criada por um princípio lá antes do tempo, né, que pode ser a luz do sol, que pode ser um rio, pode ser a ideia de dia, pode ser o tempo, pode ser o mar, enfim, um princípio. E esses princípios assumem formas culturais especificas." (Paulo).

\footnotetext{
8 Pentagrama: Símbolo popularmente utilizado entre (neo)Pagãos ecléticos ou Wiccas, trata-se de uma estrela de cinco pontas com um círculo ao seu redor.

9 Triskelion: Símbolo que possui três pernas que partem de um centro em comum. Segundo Langer (2015), possui significado semelhante a diversos símbolos solares existentes desde a idade do bronze até a idade média. Está conectado a sazonalidade, a vida e as divindades do céu.

10 Mjölnir: Martelo do deus nórdico Thor, conhecido por ser a principal arma da qual esse deus fazia uso para eliminar seus "inimigos", os gigantes. (LANGER, 2015, p. 302).
} 
Para Berger (1999), há um elemento fundamental nesse processo de compreensão subjetiva entre os(as) praticantes, a qual pode ser interpretada como uma forma "mística-de-ser-no-mundo". Ser-nomundo é um conceito chave para se compreender as diferentes formas de existir e os processos subjetivos de significação e atribuição de sentido às coisas. Segundo Ferreira (2010), o referido conceito está relacionado à interação do ser humano no mundo, mediante um processo que ocorre de forma simultânea no homem-mundo e que também está implicado na condição de existência e nos processos formadores de subjetividades e significação. Em relação ao (Neo)Paganismo, a maneira "mística-deser-no-mundo" se refere a uma forma de interpretar e compreender o mundo circundante, em um sentido "mágico" relacional. Isso acontece devido ao fato de que, segundo a concepção de mundo dos praticantes do Paganismo Contemporâneo, diversos aspectos estão implicados no desenvolvimento de suas percepções da realidade, o que envolve práticas de magia, meditação, visualizações, existência e interferência de outros seres habitantes da dimensão além-do-humano.

Perceber o mundo de forma "mágica" não significa que as compreensões da realidade se constituam em sentido fantasioso ou distante do que se considera parte da "realidade" concreta, mas que, diante dessa percepção, os praticantes interagem e buscam sentido aos processos de suas vidas particulares a partir de práticas que os ajudam a atribuir sentido às coisas. Sobre essa percepção, Paulo relata que, ao praticar Wicca e Bruxaria, a vivência da experiência religiosa o modifica e passa a moldar a forma como ele se percebe enquanto pessoa, além de proporcionar um aprofundamento da consciência, levando à conexão com as "partes" mais profundas de quem é. $\mathrm{O}$ entrevistado também diz que estas mudanças de percepção da realidade o ajudaram no seu processo de autoconhecimento. Nas palavras dele:

“(...) processos de autodescobertas, de autoconhecimento, me levaram a lidar com questões da minha própria experiência humana é que me tornaram uma pessoa mais espiritualizada. Coisas como, por exemplo, tomar consciência, plena consciência do motivo pelo qual eu me sentia tão rejeitado. (...) foi um processo que se deu dentro do corpo dessa espiritualidade e que me tornou uma pessoa melhor, me faz uma pessoa melhor." (Paulo).

Para muitos (Neo)Pagãos, as práticas religiosas ajudam a fazer contato com aspectos profundos de suas mentes. Pike (2001) ressalta que tais compreensões se manifestam na crença de que os rituais e práticas religiosas possibilitam uma interconexão das diversas camadas do Self, incluindo vidas passadas e conexão com outros seres e entidades existentes dentro do universo (Neo)Pagão. Em seu estudo, a autora analisa os significados atribuídos, pelos praticantes, aos festivais sazonais, defendendo serem eles ocasiões de "self-expressão", o que abarca a relação dos praticantes com seus corpos, com a sexualidade, com o desenvolvimento e com o fortalecimento da comunidade. A expressão do Self é possibilitada quando os praticantes se sentem seguros, no sentido de poderem agir de forma "natural", dentro daquilo que acreditam, quando partilhado com outros semelhantes de suas comunidades. Desta forma, os praticantes não se sentem "esquisitos" ao serem inseridos em uma situação ritualística em que os conflitos do "mundo mundano" são trabalhados em conjunto e, por fim, passam a ser deixados de fora - aspecto amplamente apontado pelos(as) participantes.

Outro aspecto importante da interação em realidades religiosas está no fato de que a situação ritualística, quando experienciada com outros praticantes, promove um senso de pertencimento à comunidade. Pike (2001) explica que, em meio a essas produções de sentidos, as vivências de "marginalização" da realidade (Neo)Pagã propiciam união da comunidade. Segundo a autora, é comum encontrar, nesse grupo religioso, relatos de exclusão ou de autopercepção como "outsiders", quando adolescentes, o que ocorre por diversos fatores. Lembremos que muitos deles se sentem diferentes, se vestem de maneira diferente, têm preferência por hobbies como vídeo games, RPG (jogos de interpretação de papéis), e manifestam grande afinidade para com o mundo fantástico e a temática ocultista. Nesse sentido, a comunidade fortalecida dos (Neo)Pagãos se torna um lugar de pertencimento e reconhecimento de seus sentidos, já que esses praticantes trazem em suas experiências vários relatos de exclusão. Para Arthur, as celebrações religiosas são importantes por serem situações de convívio social e, segundo ele:

“(...) além de ser uma celebração religiosa, o ritual em grupo é um convívio social, é algo que você tá ali com pessoas que você se identifica, né, e que fortalece esses laços de amizade entre as pessoas, (...) é um evento social importante e praticando sozinho não há." (Arthur).

O relato de Arthur possibilita compreender a importância do sentido de comunidade para os (Neo)Pagãos, sendo importante ressaltar que parte dos praticantes não pertencem a um grupo religioso e mantém suas práticas de forma solitária. Este é o caso do entrevistado citado, que relata ter pertencido a um grupo, mas que, devido às rotinas dos integrantes e aspectos particulares da vida de cada um, já não se reúnem mais. Arthur acrescenta que 
a prática solitária não é de todo ruim e possui seus aspectos positivos, ainda que a parte relacional se mantenha de fora. Para ele, a carga emocional que o praticante intenciona em seu ritual pode ser intensa, já que não se trata de uma situação corriqueira da vida ordinária, dependendo apenas do próprio praticante sacralizar o momento. Essa compreensão, sobre a prática solitária, possibilita uma experiência de responsabilização do (Neo)Pagão em relação ao modo como irá conduzir e significar a sua prática religiosa. O Paganismo Contemporâneo possibilita, em sua proposta, uma criatividade para lidar com as situações diversas, assim como permite adaptações e novas formulações de como cada praticante pode compreender e conduzir suas experiências.

\section{Considerações Finais}

O presente trabalho almejou compreender as experiências dos(as) praticantes do Paganismo Contemporâneo e suas relações com as práticas espirituais. Foi discutido como estes adeptos entendem e significam sua relação com a natureza e como se percebem enquanto pertencentes a uma crença holística. Nos relatos, constatou-se, com ênfase, a relação que possuem com o mundo e a conexão com a natureza. A questão da sacralidade foi um ponto importante a ser ressaltado, já que, para os/as praticantes, o divino-está-no-ser e o ser-estáno-mundo, compreendendo a relação do mundo natural com o mundo humano e com o mundo dos Deuses enquanto partes constituintes e inseparáveis de uma mesma realidade.

O estudo permitiu compreender a experiência de praticantes do Paganismo Contemporâneo e como estes o percebem enquanto sistema de crenças diverso e plural que diz respeito a uma forma específica de compreensão de mundo. O Paganismo Contemporâneo, como crença holística buscada pelos(as) seus praticantes, se faz de barreiras fluidas e conceitos não sistematizados sobre a natureza, pois se trata de uma religião "sem dogmas" que permite uma diversidade de "sistematizações" e interpretações entre os diferentes grupos ou praticantes solitários. Sendo assim, o Paganismo Contemporâneo aglomera crenças religiosas que se expandem em diversas possibilidades, permitindo atualização e criação de novos conceitos e novas compreensões de mundo. Do mesmo modo, os(as) praticantes se possibilitam na inserção de inúmeros elementos e discursos que podem estar ou não relacionados às propostas iniciais de suas religiões.

A relação com o vivo, com o mundo e com a natureza está fortemente relacionada e conectada com todas as coisas que existem. Logo, nessa concepção, o homem (divino) e a natureza (divina) não se separam. Para os(as) praticantes, o sagrado está em você mesmo, o sagrado está no todo. E esta relação e este aspecto religioso possibilitam, a eles, o entendimento de si mesmos enquanto seres responsáveis pelas suas escolhas e seu agir. Além disso, a relação com o mundo natural é compreendida como um aspecto fundamental para entender o Paganismo Contemporâneo. As práticas religiosas possibilitam uma interconexão das diversas camadas do self, assim como propõe um lugar de "self-expressão", incluindo a relação dos praticantes com seus corpos, com a sexualidade, com o desenvolvimento e o fortalecimento da comunidade.

Os relatos dos(as) participantes demonstrou o despertar do interesse em se conhecimentos quanto a diferentes práticas religiosas e a processos de subjetivação decorrentes das experiências espirituais. Acredita-se que, em estudos futuros, seja possível, também, ampliar o número de participantes e a quantidade de entrevistas, para acessar pessoas com diferentes realidades, como, por exemplo, a classe social dos(as) praticantes, faixa etária, sexo, o tempo de prática holística, distintos grupos de pertença, dificuldades encontradas nas práticas, preconceitos vividos, relação com pares e díspares, entre outros aspectos que as limitações desse estudo não permitiram abarcar.

Por fim, espera-se que este trabalho possibilite novos olhares e que seja uma contribuição ao tema, ainda pouco estudado no Brasil. Compreende-se que, por um lado, o olhar da Psicologia acerca da compreensão dos processos de subjetivações pode contribuir para uma aproximação dos sentidos e significados que os (Neo)Pagãos podem atribuir às suas experiências religiosas. Por outro lado, anseiase que a Psicologia e seus profissionais se abram para novas possibilidades de compreensão da dimensão religiosa e se atentem a grupos ainda com pouca visibilidade nos espaços sociais e, por conseguinte, no meio acadêmico, como é o caso dos (Neo)Pagãos.

\section{Referências}

Amatuzzi, M. (2010). Por uma psicologia humana. Campinas: Editora Alínea.

Berger, H. (1999). A Community of Witches: Contemporary Neo-paganism and Witchcraft in the United States Studies in Comparative Religion. Columbia: University of South Carolina Press.

Brandão, H. H. N. (2004). Introdução à análise do discurso. 2. ed. rev., Campinas: Editora Unicamp.

Clifton, C. (2009). Earth day and Afterwards: American Paganism's Appropriation of "Nature Religion". Em: M. Pizza \& J. R. Lewis (Ed.), Handbook of contemporary paganism (p. 109-118). Boston: Brill.

Ferreira, A. M. C. (2010). O destino como Serenidade. Revista de Filosofia, v. 30, n. 97, p. 249-262. 
Freitas, M. H. (2014). Religiosidade e saúde: Experiências dos pacientes e percepções dos profissionais. Revista Pistis e Práxis: Teologia e Pastoral, v.6, n.1, p. 89-105.

Geertz, C. (2008). A interpretação das culturas. Rio de Janeiro: LTC.

Goodman, L. (2011). Comment: On respondent-driven sampling and snowball sampling in hard-toreach populations and snowball sampling not in hard-to-reach populations. Sociological Methodology, v. 41, n.1, p. 347-353.

Guerrieiro, S. et. al. (2020). Concepções de saúde, cura e doença no ethos nova era: um estudo piloto entre terapeutas holísticos de São Paulo e Florianópolis. Goiânia, v. 18, n. 1, p. 106-119.

Gunnell, T. (2015). Occasional Rituals of the Ásatrúarfélag in Iceland. In: Minniyakhmetova, T; Velkoborská, K. The ritual year 10: magic in rituals and rituals in magic. Innsbruck-Tartu: ELM Scholarly Press, p. 28-40.

Harvey, G. (2009). Animist Paganism. Em: M. Pizza \& J. R. Lewis (Ed.), Handbook of contemporary paganism (p. 393-411). Boston: Brill.

Harvey, G. (2014). The handbook of contemporary animism. London: Routledge.

Hood, R., Hill, P. \& Spilka, B. (2009). The psychology of religion: An empirical approach. Guilford Press, 2009.

Koenig, h. g.; Mccullough, m.; Larson, d. (2012). Handbook of religion and health: a century of research reviewed. New York: Oxford University Press.

Koenig, H.G. (2015). Religion, spirituality, and health: a review and update. Advances, v.29, n. 3, p. 1118, Summer.

Langer, J. \& Campos, L. (2007). The Wicker Man: reflexões sobre a wicca e o neo-paganismo. Fênix: Revista de História e Estudos Culturais, v. 4, p. 0121.

Langer, J. (2010). Asatrú: Um Guia Essencial Para o Paganismo Nórdico. Revista Brasileira de História das Religiões, v. 3, n. 7, p. 359-362. Resenha.

Langer, J. (2015). Dicionário de Mitologia Nórdica. São Paulo: Hedras.

Paiva, G. J. (1998). Estudos psicológicos da experiência religiosa. Temas em Psicologia, v. 6, n. 2, p. 153160.

Pike, S. M. (2001). Earthly bodies, magical selves: Contemporary pagans and the search for community. California: University of California Press.
Ribeiro, J. (2009). Holismo, ecologia e espiritualidade: caminhos de uma Gestalt plena. São Paulo: Summus.

Strmiska, M. (2005). Modern Paganism in world cultures: comparative perspectives. In: Strmiska, M. Modern Paganism in world cultures: comparative perspectives. United States of America: Abc-clio, p. 1-53.

Tsugami, S. (2019). Deus para mim é Odin: O Paganismo Nórdico Contemporâneo no Brasil. (Dissertação de Mestrado em Ciências das Religiões). Universidade Federal da Paraíba.

White, E. (2016). Theoretical, Terminological, and Taxonomic Trouble in the Academic Study of Contemporary Paganism: A Case for Reform. Pomegranate, v. 18, n. 1, p. 31-59.

York, M. (2003). Pagan theology: Paganism as a world religion. New York: NYU Press.

York, M. (2004). Historical Dictionary of New Age Movements. United States of America: The Scarecrow Press, Inc. Lanham, Maryland, and Oxford.

Susan Sanae Tsugami (Orcid 0000-0003-2697-2900). Possui Graduação em Psicologia pela Universidade Católica de Brasília, Especialização em Gestalt-terapia pelo Instituto de Gestalt-terapia de Brasília, Mestrado em Ciências das Religiões pela Universidade Federal da Paraíba e é Doutoranda pelo mesmo programa. Tem experiência na área de Psicologia, com ênfase em Psicologia Clínica, atuando principalmente nos seguintes temas: saúde mental, Gestalt-terapia, religião, paganismo nórdico, (Neo) Paganismo e folclore. Membro Neve (Núcleo de Estudos Vikings e Escandinavos). Email: tsugamisanae@gmail.com

Luciana Santos (Orcid 0000-0002-2280-3483). Doutora e Mestre pelo Programa de Pós-Graduação em Psicologia Clínica e Cultura da Universidade de Brasília. Psicoterapeuta fenomenológica-existencial, formadora de psicoterapeutas e supervisora com enfoque em teorias humanistas e saúde mental. Tem formação e experiência em Psicoterapia Fenomenológica-Existencial, processos de adoecimento e saúde mental, gênero, cultura e subjetividade.Email: lucianasantospsi@gmail.com

Recebido em 23.10.2018

Primeira Decisão Editorial em 29.04.2019 Segunda Decisão Editorial em 17.02.2020 Aceito em 21.07.2020 